\title{
Renal cell carcinoma metastatic to the duodenum: Treatment by classic pancreaticoduodenectomy and review of the literature
}

\author{
Robert Adamo \\ Thomas Jefferson University \\ Patrick J. Greaney Jr. \\ Thomas Jefferson University \\ Agnieszka Witkiewicz \\ Thomas Jefferson University \\ Eugene P. Kennedy \\ Thomas Jefferson University \\ Folipletwis arpepadditional works at: https://jdc.jefferson.edu/surgeryfp \\ Thomas Jefferson University \\ Part of the Surgery Commons \\ Let us know how access to this document benefits you
}

\section{Recommended Citation}

Adamo, Robert; Greaney, Patrick J. Jr.; Witkiewicz, Agnieszka; Kennedy, Eugene P.; and Yeo, Charles J., "Renal cell carcinoma metastatic to the duodenum: Treatment by classic pancreaticoduodenectomy and review of the literature" (2007). Department of Surgery Faculty Papers. Paper 8.

https://jdc.jefferson.edu/surgeryfp/8

This Article is brought to you for free and open access by the Jefferson Digital Commons. The Jefferson Digital Commons is a service of Thomas Jefferson University's Center for Teaching and Learning (CTL). The Commons is a showcase for Jefferson books and journals, peer-reviewed scholarly publications, unique historical collections from the University archives, and teaching tools. The Jefferson Digital Commons allows researchers and interested readers anywhere in the world to learn about and keep up to date with Jefferson scholarship. This article has been accepted for inclusion in Department of Surgery Faculty Papers by an authorized administrator of the Jefferson Digital Commons. For more information, please contact: JeffersonDigitalCommons@jefferson.edu. 


\section{Renal Cell Carcinoma Metastatic to the Duodenum: Treatment by Classic Pancreaticoduodenectomy and Review of the Literature}

Robert Adamo MD ${ }^{1}$, Patrick J. Greaney, Jr. MD ${ }^{1}$, Agnieszka Witkiewicz MD ${ }^{2}$, Eugene P. Kennedy $\mathrm{MD}^{1}$, and Charles J. Yeo MD ${ }^{1}$

Departments of Surgery ${ }^{1}$ and Pathology ${ }^{2}$, Thomas Jefferson University, Philadelphia, PA

Presented as a poster at the $41^{\text {st }}$ Annual Meeting of the Pancreas Club, May $20^{\text {th }}$, 2007, Washington D.C.

Corresponding Author:

Charles J. Yeo, M.D.

Samuel D. Gross Professor and Chair

Department of Surgery

Jefferson Medical College

1015 Walnut Street; Suite 620

Philadelphia, PA 19107

(215) 955-8643 (phone)

(215) 923-6609 (fax)

Email: charles.yeo@jefferson.edu 


\begin{abstract}
Renal cell cancer (RCC) most commonly metastasizes to the lungs, bones, liver, renal fossa and brain, although metastases can occur elsewhere. RCC metastatic to the duodenum is especially rare, with only a small number of cases reported in the literature.

Herein, we describe a case of an 86 year old female with a history of RCC treated by radical nephrectomy 13 years previously. The patient presented with duodenal obstruction and anemia from a solitary duodenal mass invading into the pancreas, and was treated via classic pancreaticoduodenectomy. Preoperative imaging and intraoperative assessment showed no evidence of other disease. Pathology confirmed metastatic RCC without lymph node involvement. Our case report and review of the English language literature underscore the rarity of this entity and supports aggressive surgical treatment in such patients.
\end{abstract}

Key words: renal cell carcinoma, pancreaticoduodenectomy, metastases, duodenum 


\section{INTRODUCTION}

Renal cell carcinoma (RCC) commonly metastasizes to sites such as lung, lymph nodes, liver, pancreas, bone, brain, contralateral kidney and adrenal glands (1). Autopsy studies have shown that metastatic disease of any type to the small intestine is unusual and accounts for only 1-2\% of all metastases. Approximately $7 \%$ of small bowel metastatic lesions are of renal cell origin (2). RCC metastatic to the pancreas has been frequently reported (3-5). Solitary metastasis from RCC to the duodenum is exceedingly rare. Commonly, renal cell metastases present many years after initial treatment, with recurrences reported up to 17.5 years after initial surgery (6). Most cases of duodenal metastasis from RCC present with upper gastrointestinal bleeding or obstructive symptoms, and sequelae may include anemia, melena, fatigue and early satiety. Several treatments of solitary RCC metastasis have been reported. These include a variety of surgical and interventional therapy options that have been shown to provide effective survival benefits. Herein, we report a case of an 86 year-old woman with metastatic RCC confined to the duodenum, with successful complete resection by classic pancreaticoduodenectomy.

\section{CLINICAL MATERIAL}

An 86-year-old woman with a past medical history notable for hypertension and RCC 13 years status post right radical nephrectomy, presented to her primary care physician with fatigue. When found to be anemic, she was treated with iron supplementation. Several months later she continued to have 
fatigue, anorexia, early satiety, and weight loss of approximately 6 pounds and was found to have heme-positive stools. Jaundice and pancreatitis were absent. The patient underwent a capsule endoscopy, however the capsule never left the stomach. The patient then had an EGD, which showed an ulcerated mass involving the distal antrum and proximal duodenum. Biopsy of the ulcerated mass was consistent with metastatic RCC. An abdominal CT scan (Figure 1) showed a large soft tissue mass at the level of the gastric antrum and duodenal bulb, no evidence of liver metastasis, and her visceral vessels appeared normal. She was scheduled for surgical resection, and received perioperative prophylactic antibiotic, subcutaneous heparin and sequential compression devices. At the time of operation, exploration of the duodenum and head of the pancreas revealed a mass clearly located in the proximal duodenum with involvement of the head of the pancreas and distal antrum. There was no evidence of malignant ascites, carcinomatosis, omental implants, or involvement of the liver. Attempts were made to dissect the tumor free of the head of the pancreas, however the duodenal mass was adherent to and invading into the pancreas. A classic Whipple procedure was performed and the resultant specimen was sent for pathologic evaluation. Postoperatively, the patient's hospital course was complicated by hypoxemia and bilobar pulmonary emboli treated with appropriate anticoagulation. Ultimately, the patient was discharged to a rehabilitation facility on post-operative day sixteen in stable condition, doing well. In follow up the patient is leading an active life and continues to do well, now 7 months following resection, without evidence of further metastatic disease. 


\section{PATHOLOGY}

Gross examination of the classic pancreaticoduodenectomy specimen revealed a $9 \times 5.5 \times 3 \mathrm{~cm}$ tan-red polypoid, pedunculated tumor protruding into the duodenum (Figure 2). The tumor involved the full thickness of duodenal wall and invaded into the pancreatic head (Figures 3 and 4). Microscopically the tumor was composed of clear cells arranged in a trabecular and alveolar pattern. The tumor cells had centrally located small nuclei with inconspicuous nucleoli and were surrounded by a prominent vascular network (Figure 5). Eight lymph nodes were identified in the resection specimen, and all were negative for metastatic tumor.

\section{DISCUSSION}

Metastatic RCC to the duodenum is extremely rare. For the purposes of this report we have included patients with the bulk of the gross tumor in the duodenal or ampullary regions, distinct from pancreatic involvement. Our review of the English language literature (using keywords including: renal cell carcinoma, solitary, metastasis, duodenum and ampulla), yielded 16 reports of solitary duodenal/ampullary renal cell metastases (Table 1). The mean time period from nephrectomy to diagnosis of these solitary metastases was 8 years, with our patient having a 13 year interval between initial resection and recurrence. The most common presentation of these patients was gastrointestinal bleeding (69\%), while a minority presented with pain, jaundice, or early satiety. 
RCC can spread via lymphatic or hematogenous spread, as well as by direct invasion into adjacent anatomic structures (7). The pancreas is an unusual site of metastatic disease for other tumors, but it is common in RCC. The duodenum is a particularly rare site of metastasis in $\mathrm{RCC}$, which is perhaps counterintuitive given its retroperitoneal proximity to the right kidney.

The natural history of RCC is unpredictable. Disease eradication and cure are possible after nephrectomy, however, there is also the possibility of a long period of disease latency, followed by recurrence of metastatic disease at unsuspected anatomic locations (1). As such it is imperative to remain vigilant in post-nephrectomy patients upon presentation of new clinical symptoms. When metastatic RCC involves the duodenum, it most commonly is located in the periampullary region or the duodenal bulb (8). The presenting symptoms in these rare cases typically include gastrointestinal bleeding, anemia, fatigue, obstruction with early satiety or jaundice. Our patient initially presented with fatigue and was found to be anemic with heme-positive stools. Any patient with gastrointestinal symptoms and a history of RCC should undergo full diagnostic work-up with both radiologic and endoscopic evaluation (9). Endoscopy allows for biopsy of suspicious lesions and is mandatory for this subset of patients.

Surgical treatment of solitary RCC metastasis has been shown to improve survival $(3,4,5,10,11)$. Therapeutic goals include complete metastatectomy whenever surgically feasible. Several case series have been reported of successful surgical treatment of solitary pancreatic RCC metastases $(3,4)$, however few isolated reports of excision of duodenal or ampullary metastases exist in the 
literature. Procedures ranging from classic pancreaticoduodenectomy (Whipple procedure) to interventional embolization have been reported (Table 1). In patients with massive gastrointestinal bleeding secondary to metastatic duodenal RCC, arteriography with embolization of the gastroduodenal artery has been described (12). Our patient had isolated proximal duodenal involvement with adherence to the head of the pancreas making it impossible to separate the duodenal/pancreatic border. Thus, given the involvement of the mass with the proximal duodenum, a classic pancreaticoduodenectomy was performed, with successful excision of all involved structures with clear margins, and with no lymph node involvement. In fact, all resection specimens from all reviewed case reports have revealed no lymph node involvement (Table 1).

In summary, solitary metastatic RCC to the duodenum is extremely rare. Appropriate awareness and aggressive work-up of gastrointestinal symptoms in patients post-nephrectomy for RCC is of paramount importance. In this subgroup of patients with symptoms of GI bleeding, fatigue, anemia, early satiety or obstruction, all should undergo complete endoscopic evaluation, as well as radiologic investigation to evaluate for the presence of, and the extent of metastatic disease. Any patient with solitary metastatic RCC to the duodenum should be considered a candidate for complete surgical excision if medically and technically feasible, both for palliation of symptoms and because it provides the opportunity for meaningful disease free survival. 


\section{REFERENCES}

1. Ritchie AWS, Chisholm GD. The natural history of renal cell carcinoma. Seminars in Oncology 1983; 10:390-400.

2. Willis RA. Secondary tumors of the intestines. In: The Spread of Tumors in the Human Body, $3^{\text {rd }}$ edition, 1973. London: Butterworth \& Co., Ltd., Chapter 21:209-213.

3. Le Borgne J, Partensky C, Glemain P, Dupas B, de Kerviller B.

Pancreaticoduodenectomy for metastatic ampullary and pancreatic tumors. Hepato-Gastroenterology 2000; 47:540-544.

4. Sohn TA, Yeo CJ, Cameron JL, Nakeeb A, Lillemoe KD. Renal cell carcinoma metastatic to the pancreas: Results of surgical management. Journal of Gastrointestinal Surgery 2001, 5(4): 346-351.

5. Yeo CJ, Cameron JL, Sohn TA, et al. Six hundred fifty consecutive pancreaticoduodenectomies in the 1990s: Pathology, complications, and outcomes. Annals of Surgery. 1997;226:248-260.

6. Janzen RM, Ramj AS, Flint JDA, Scudamore CH, Yoshida EM. Obscure gastrointestinal bleeding from an ampullary tumor in a patient with a remote history of renal cell carcinoma: A diagnostic conundrum. Can J Gastroenterology. 1998; 12(1):75-78. 
7. Chang WT, Chai CY, Lee KT. Unusual upper gastrointestinal bleeding due to late metastasis from renal cell carcinoma: a case report. Kaohsiung J Med Sci. 2004; 20(3):137-41.

8. Loualidi A, Spooren PFMJ, Grubben MJAL, Blomjous CEM, Goey SH.

Duodenal metastasis: an uncommon cause of occult small intestinal bleeding. The Netherlands Journal of Medicine 2004; 62(6):201-205.

9. Nabi G, Gandhi G, Dogra PN. Diagnosis and management of duodenal obstruction due to renal cell carcinoma. Trop Gastroenterol. 2001; 22(1):47-9. 10. Freedman AI, Tomaszewski JE, Van Arsdalen KN. Solitary late recurrence of renal cell carcinoma presenting as duodenal ulcer. Urology. 1992; 39(5):461-3.

11. Toh SK, Hale JE. Late presentation of a solitary metastasis of renal cell carcinoma as an obstructive duodenal mass. Postgrad Med J. 1996; 72(845):178-9. 12. Lynch-Nyhan A, Fishman EK, Kadir S. Diagnosis and management of massive gastrointestinal bleeding owing to duodenal metastasis from renal cell carcinoma. J Urol. 1987;138(3):611-3.

13. Lawson LJ, Holt LP, Rooke HWP. Recurrent duodenal hemorrhage from renal cell carcinoma. British Journal of Urology. 1966, 38:133-137.

14. Leslie KA, Tsao JI, Rossi RL, Braasch JW. Metastatic renal cell carcinoma to ampulla of Vater: an unusual lesion amenable to surgical resection. Surgery 1996; $119(3): 349-51$.

15. Venu RP, Rolny P, Geenen JE, Hogan WJ, Komorowski RA, Ferstenberg R. Ampullary tumor caused by metastatic renal cell carcinoma. Digestive Diseases and Sciences 1991; 36:0 376-378. 


\section{FIGURE LEGENDS}

Figure 1:

Non-IV contrast CT image indicating (white arrow) large soft tissue structure at level of the gastric antrum and duodenal bulb (note prior right nephrectomy with absence of the right kidney).

Figure 2:

Gross specimen revealing a $9 \times 5.5 \times 3 \mathrm{~cm}$ tan-red polypoid, pedunculated tumor protruding into the duodenum. The distal gastric specimen $(\mathrm{G})$ is to the right, the $2^{\text {nd }}$ portion of the duodenum is to the left $\left(D_{2}\right)$, and the pylorus $(P)$ is noted.

Figure 3:

Duodenal wall with Brunner's glands (black arrow) and invading tumor (white arrow). (H\&E - 100x magnification)

Figure 4:

Metastatic renal cell carcinoma (black arrows) within pancreas (white arrow) with reactive fibrosis. (H\&E - 100x magnification)

Figure 5:

The tumor was composed of clear cells arranged in trabecular and alveolar patterns. The tumor cells had centrally located small nuclei with inconspicuous nucleoli, and were surrounded by a prominent vascular network. (H\&E - 400x magnification) 


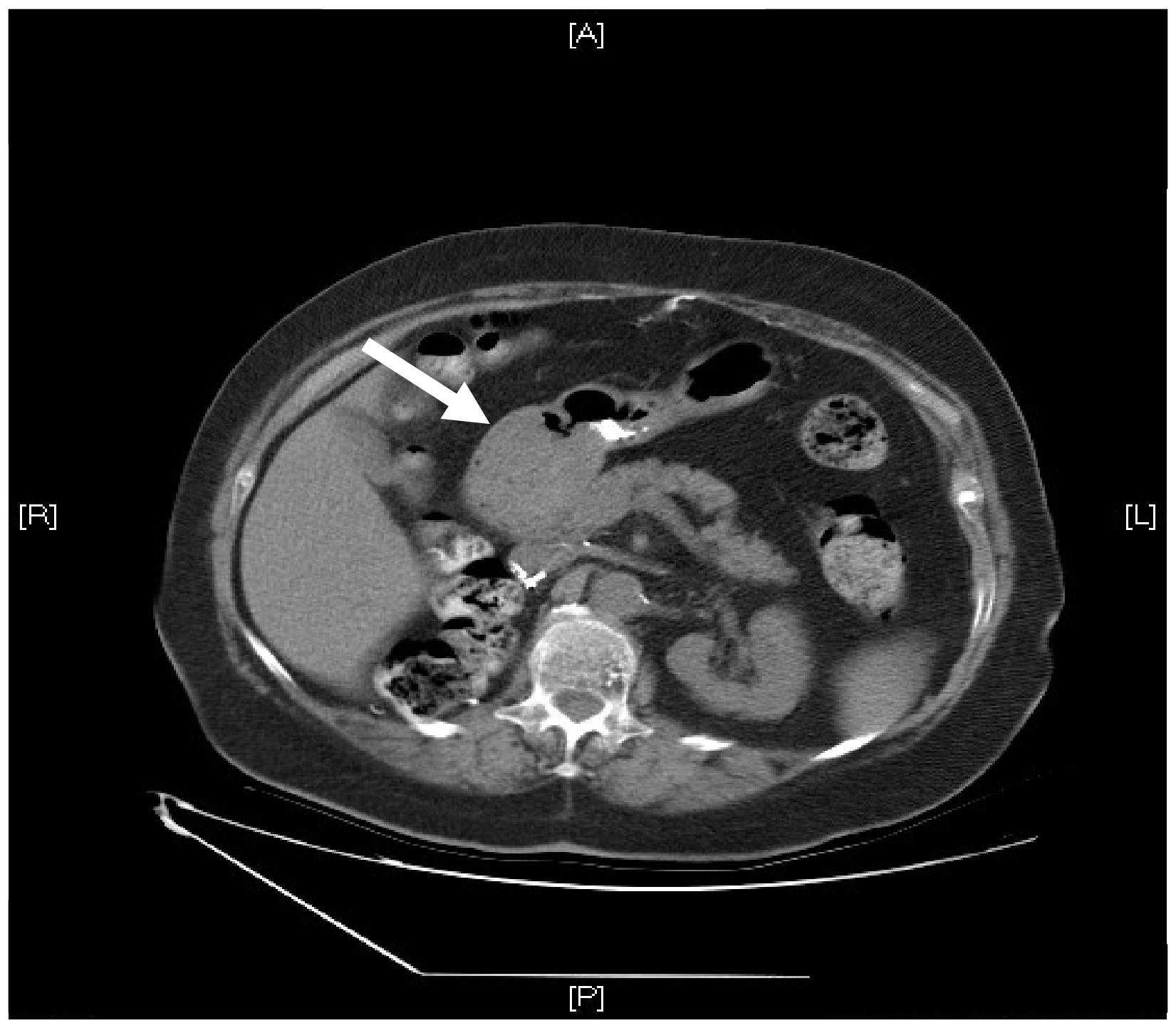

Figure 1 


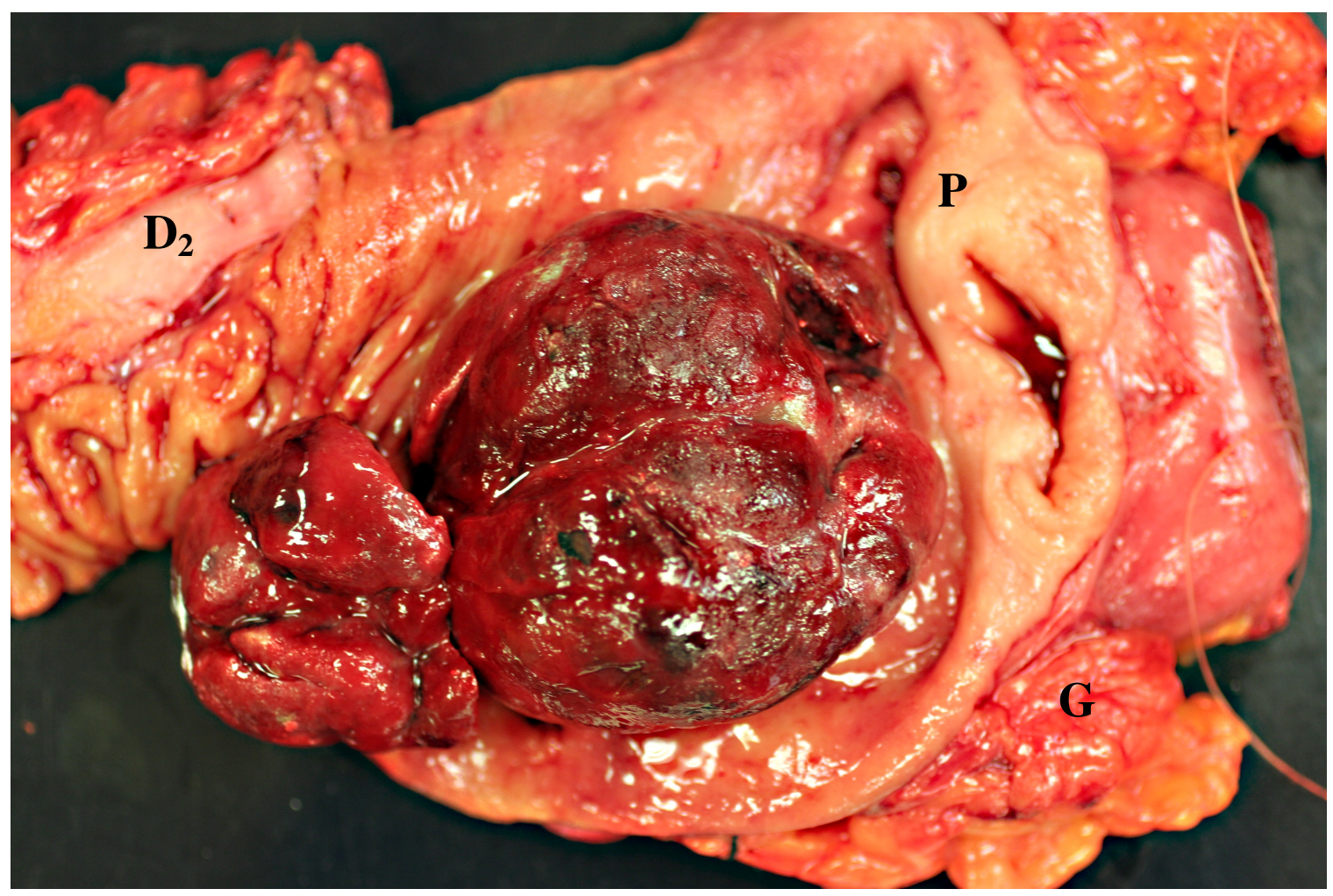

Figure 2 


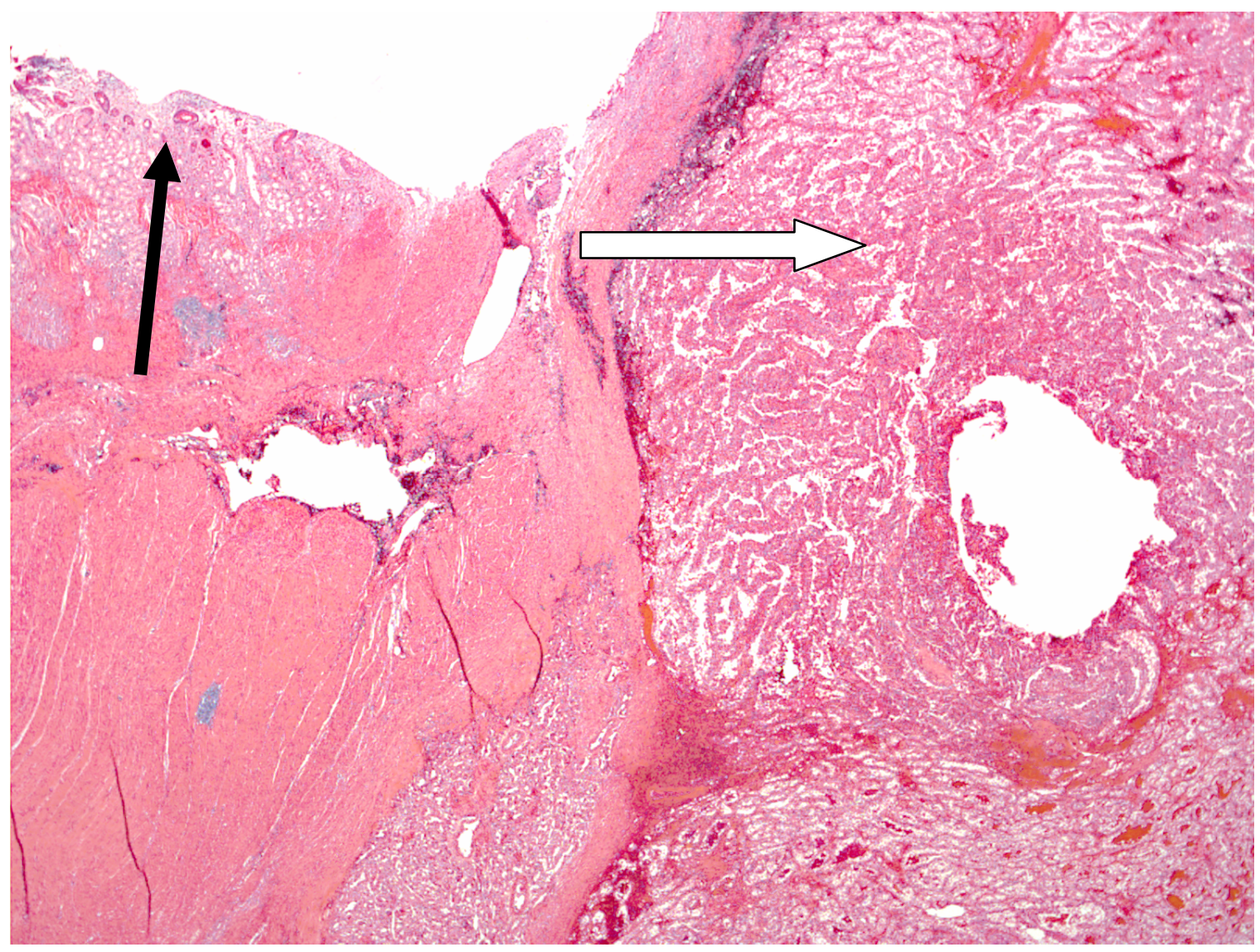

Figure 3 


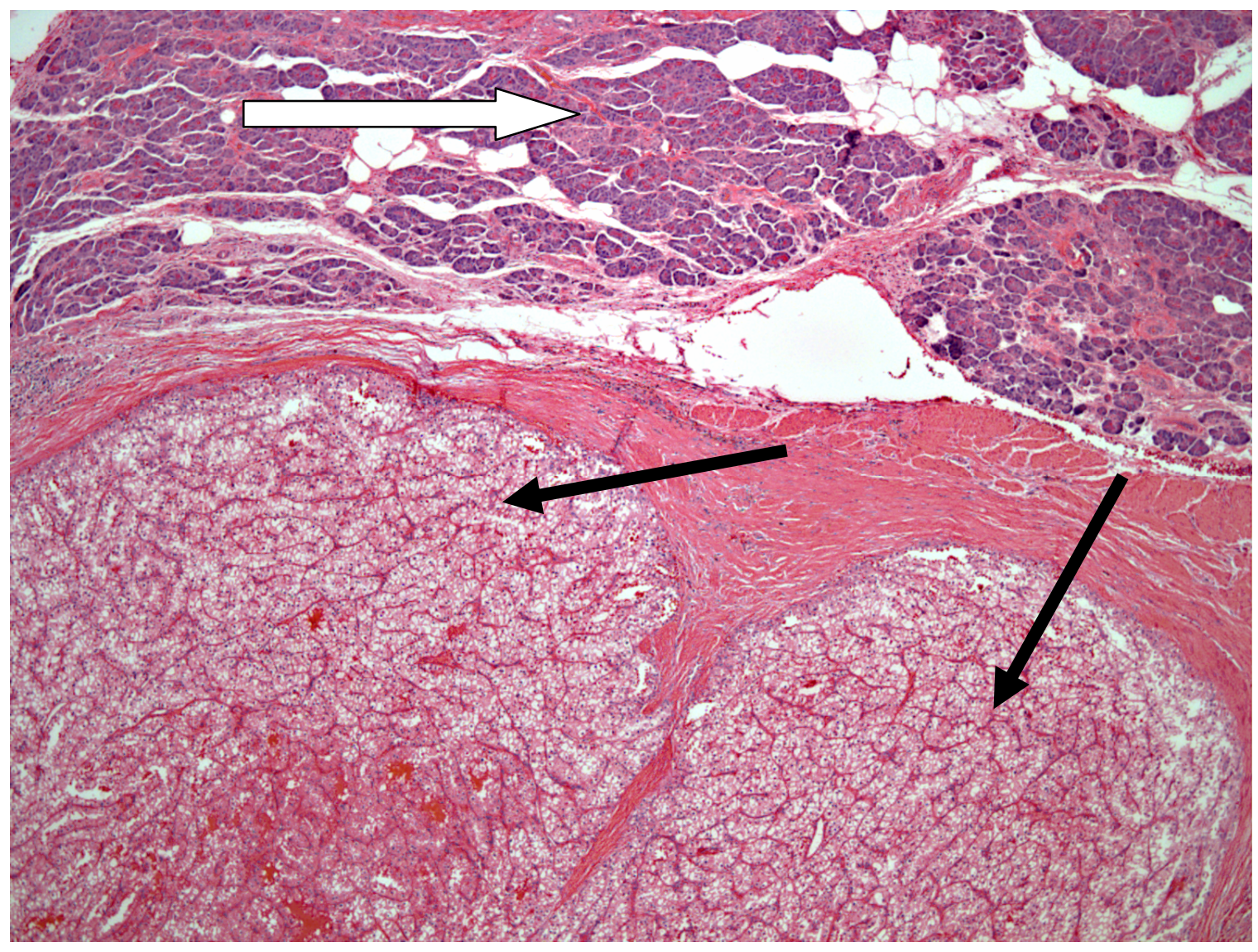

Figure 4 


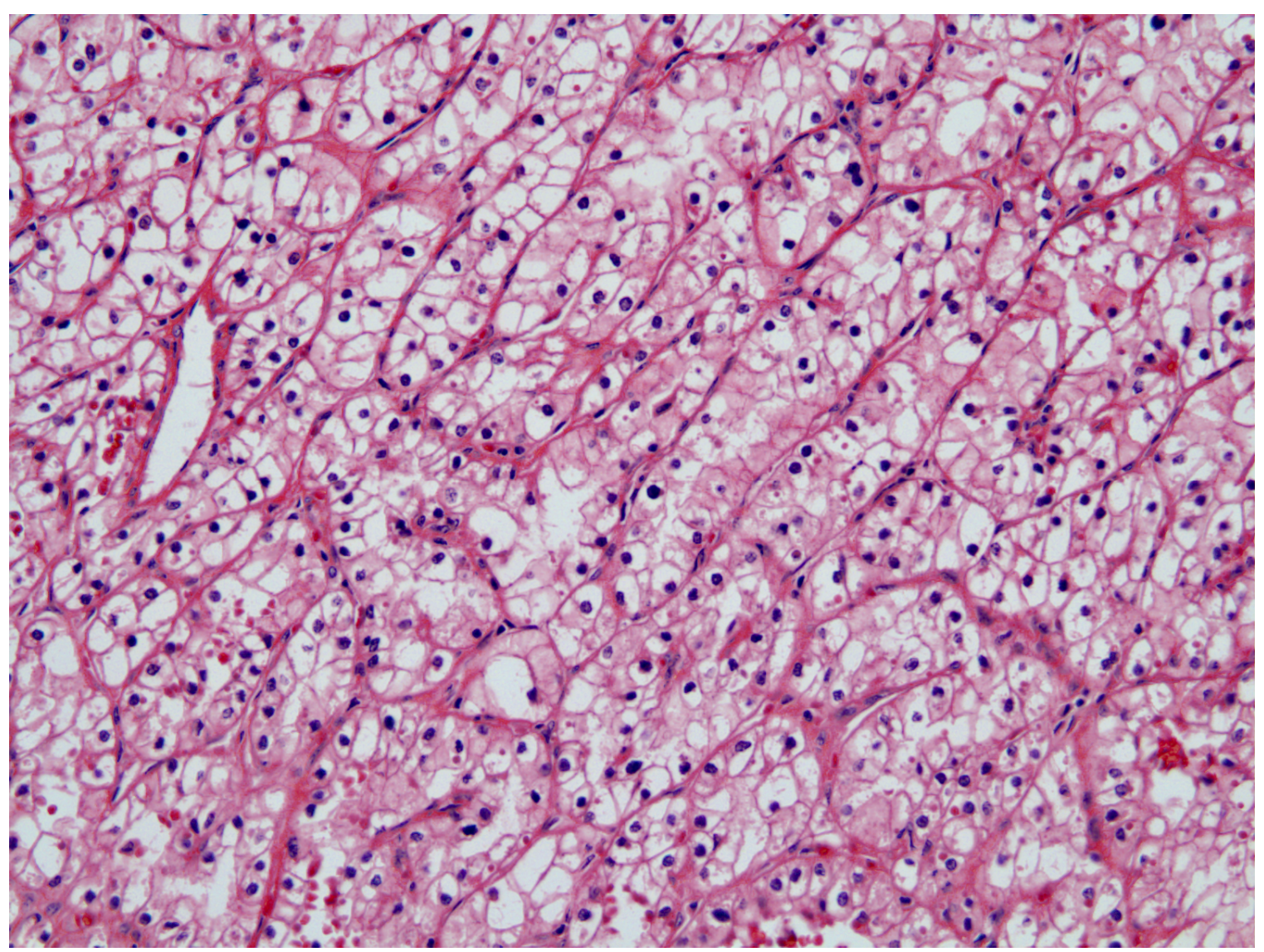

Figure 5 